\title{
ZIGBEE PHASE SHIFT MEASUREMENT APPROACH TO MOBILE INSPECTION ROBOT INDOOR POSITIONING TECHNIQUES
}

\author{
Michal SMIEJA \\ University of Warmia and Mazury in Olsztyn, Faculty od Technical Science, 46A Sloneczna str. \\ 10-710 Olsztyn, Poland, e-mail: smieja@uwm.edu.pl \\ Abstract \\ This paper presents the new approach to ZigBee ranging against the background of currently using \\ techniques. This new approach involves a phase shift measurement instead of standard time of arrival or radio \\ signal strength approaches. The ZigBee device used in this study and preliminary tests of ranging and \\ positioning performed using phase shift measurements are presented. The positioning results encourages for \\ further research on the performance verification and algorithms for processing of ranging results.
}

Key words: indoor positioning, phase shift measurements, ZigBee

\section{WYKORZYSTANIE POMIARU PRZESUNIECCIA FAZOWEGO W TRANSMISJI ZIGBEE DO POZYCJONOWANIA MOBILNYCH ROBOTÓW INSPEKCYJNYCH}

\section{Streszczanie}

W artykule przedstawiono zmodyfikowane w stosunku do najczęściej obecnie stosowanych podejście do określania położenia obiektów wykorzystujące propagacje sygnały w protokole ZigBee. Typowe rozwiązania stosowane aktualnie w systemach lokalizacji opartych o bezprzewodowe sieci wymiany danych bazują na pomiarach czasu propagacji lub mocy sygnału. Opisane w artykule podejście odwołuje się do pomiaru przesunięcia fazowego sygnału wynikającego z wykorzystania do transmisji różnych częstotliwości.

Przedstawione $\mathrm{w}$ artykule wstępne wyniki eksperymentów uzasadniają dalsze prace nad wykorzystaniem przedstawionej metody $\mathrm{w}$ zakresie opracowania algorytmów obliczeniowych pozycjonowania oraz weryfikacji efektów w warunkach rzeczywistych.

Słowa kluczowe: pozycjonowanie w przestrzeniach zamkniętych, przesuniecie fazowe, ZigBee.

\section{INTRODUCTION}

Effectiveness of realization of wide spectrum of tasks posed to mobile robots strongly depends on the possibility to control their movement. This movement is understood as a change in robot location in reference to the coordinate frame defined by the environment and as a change in this environment caused by other moving objects. This issue is especially important for so called autonomic robots, which require a "self-awareness of its position". However in the case of remote controlled robots the feedback about robot position, trajectory or movement dynamics is very important (especially in the case of robots working in harsh environment).

Cooperative navigation is a subject that is strongly developed in robotics, where multiple platforms must be able to cooperate and to perform various tasks independently in the same geometrical space. The approach to navigation in such cases must be different from autonomous localization (e.g. dead reckoning). Several approaches to such a navigation were presented for example in $[8,28]$. Cooperative navigation is based on both localization algorithms and communication between platforms. Various approaches to navigation are used in this applications. The most common approach is to use inertial measurement units for navigation indoors, GNSS/IMU outdoors or vision systems in limited closed space. The communication between platforms is ensured using wireless systems, such as ZigBee, WiFi or Bluetooth protocols. The concept of cooperative navigation in robotics can be easily translated for human positioning applications. Such an approach is presented for example in [27] where integration of inertial sensors and "inter-agent" ranging is introduced.

Localization and navigation is particularly important in many aspects of public safety. Firefighters, police, rescue teams and military are using various localization based services. There is a continuous development of navigation and localization systems. They are starting to become available in places where navigation was previously difficult or impossible. Development of new measuring devices and navigation algorithms allows to think differently about navigation and localization. 


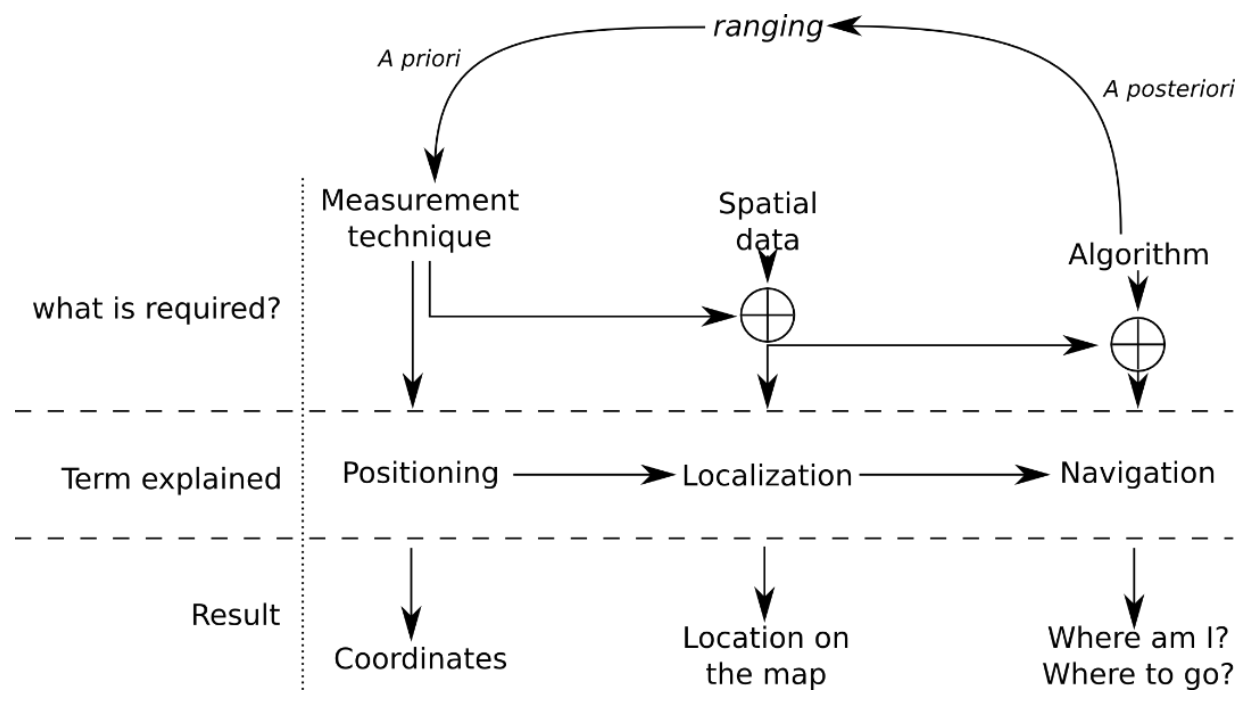

Fig. 1. Dependency between positioning, localization and navigation

The goal of this paper is to present a new approach in ranging method in RF networks. The Phase Measurement Unit (PMU) embedded into AT86RF233 ZigBee communication module extends its area of applications. The second goal of this paper is to present the results of a preliminary positioning tests.

There are few terms used in this article: ranging, positioning, localization and navigation. The relations between these terms are depicted in Fig. 1. Positioning can be understood as a measurement technology acquisition and calculation of coordinates in a fixed reference frame. After adding some spatial data to positioning (eg. maps) one obtain a position referenced to this data which will be called localization. Application of algorithms to determine the heading, velocity, time or other parameters will be called navigation. In these terms ranging can be interpreted in two ways. First one range obtained as a result of measurement technique, used for positioning (a priori ranging). Second - range obtained on the basis of the results of positioning or navigation (a posteriori ranging). This kind of ranging can be used for example to avoid collisions of robots working in the same area. Numerous solutions within this scope are adopted in many other applications where it is important to know the location of the object as well as information about a changing environment (other moving objects).

Depending on the measurement technique, positioning can be divided into range(geometry) based positioning and range(geometry) free positioning (Fig. 2). A priori ranging is used in range based positioning and a posteriori ranging can be obtained from each type of positioning. For example reflecting a group of mobile robots, realizing independent tasks in a common space and equipped with GPS receivers we would use the word positioning. However, if distances between this robots, derived from the GPS positioning results, would be used to avoid collisions, word "ranging" becomes more appropriate.

In the case of range based positioning the description of point position is described as coordinates in a fixed reference frame. It is equivalent to description of point position as a function of distances to points with known position.

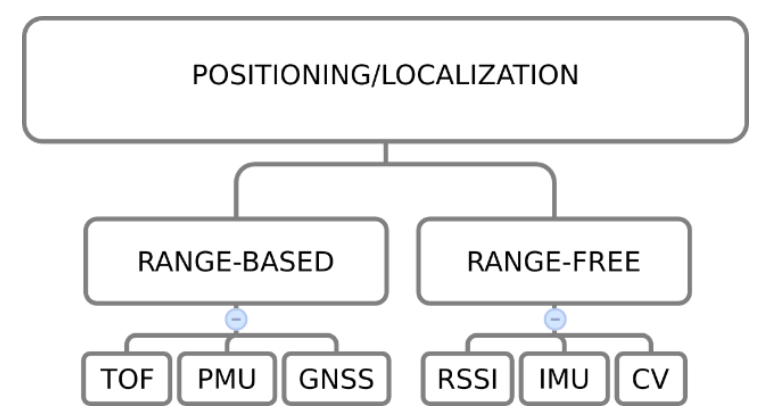

Fig. 1. Positioning methods

\section{THE COMMON RANGING MEASUREMENT METHODS}

The most well-known and widely used solution for the location of mobile objects is currently GNSS. Its dynamic expansion in navigation applications, communications and surveying, dates from March 1996 when US President Bill Clinton declared that the GPS system will be dual purpose (military and civilian).

Despite the many advantages, the GNSS systems does not cover the full area of navigation applications. The main reason are the properties of the signal propagation, which restricts the use of GNSS for open space which is free of obstacles such as walls, roofs, dense vegetation, etc. There is an ongoing research in the field of indoor GNSS navigation presented in many publications, however the accuracy of such positioning is usually lower then in outdoor applications $[17,19,30]$. 
Classical method to augment GNSS systems in the indoor applications is to use inertial navigation systems (INS). These systems are based on the measurements of craft's acceleration, orientation and gravitational forces. These values are measured using inertial measurement units (IMU) which consists of an accelerometers, gyroscopes and sometimes magnetometers. The main disadvantage of INS is the degradation of accuracy in time due to cumulating error. IMU measurements are affected with gyroscopes random walk and bias instability.

Another way of GNSS augmentation is to use pseudolites (or terralites) [5, 6, 17, 23, 24]. This ground based GNSS signal transmitters are distributed in places where there are shortages in GNSS signal, to provide line of sight propagation. The main disadvantages of this solution are a necessity to use dedicated receivers, near/far problem and algorithm modifications (in relation to standard GNSS receiver).

In case of positioning in local (or closed space) areas (small space with well determined geometry), successful and more cost effective solution is to use systems utilizing sensor devices based on ultrasound, laser or computer vision [11, 29].

Growth of network technology originally developed for the exchange of information allows for the development of network navigation. In this networks, phenomena of physical layer plays the role of information carrier about localization or positioning, as well as they are used to obtain these data.

Most of modern robots are technical objects of high complexity in which cooperation between main elements (such as sensors, executive systems, chassis or stepping system) is connected with a large flow of informations both "inside" the robot and outside communication with other objects. Due to demands of limited size, energy consumption and simplification of construction it is favourable to merge more then one functionality in one system. The integration of communication functionality together with distance measurement is one of many examples of such a merge.

The methods of using networks physical layer medium for positioning (in the case of most common near band Wi-Fi, Bluetooth or ultra wide band UWB) are connected with electromagnetic wave propagation. Time Of Arrival (TOA), Time Difference Of Arrival (TDOA), Time OF Flight (TOF), Radio Signal Strength Indication (RSSI) described in [4, 18] or Angle of Arrival [22], are all acquiring data from the physical layer of communication protocols.

An important issue, that must be taken under consideration is ranging between mobile nodes. In this aspect routing is an important issue. Due to the unpredictable nature of dynamic nodes location, associated with the displacement of the objects (robots), the range and quality of transmission between each of nodes varies with time and is random. In extreme cases, this peer-to-peer communication is not possible (for example, between very distant objects, or objects separated with obstacles). These limitations are eliminated using the method of multihop communication, where transmission between the target node and the source node is carried out using intermediate nodes, with partial, undisturbed lines of sight. Continous change in the relative position of nodes enforces the use of self-organizing, self-configuring and selfhealing networks operating in ad-hoc mode. In case of ZigBee protocol the most common is Ad-hoc ondemand distance vector (AODV) [20] routing algorithm.

$R S S I$ is one of the most commonly used range free positioning technique among $R F$ networks. The method, widely described in $[4,15,28]$, is radio signal strength of the received signal from transmitters placed at known positions. The foundation of this method is fading of signal along with increasing distance to its source, which can be denoted as:

$$
\text { PathLoss }=20 \log _{10}\left[\frac{4 \pi d}{\lambda}\right]
$$

Or using more complete equation (namely Friis equation) [31]:

$$
P_{R x}=P_{T x} \frac{G_{T x} G_{R x} \lambda^{2}}{16 \pi^{2} d^{2} L}
$$

where $P_{R x}$ is received power, $P_{T x}$ is transmitted power, $G_{R x}$ and $G_{T x}$ are receiver and transmitter antenna gain respectively, $\lambda$ is a wavelength, $d$ is a distance and $L$ is a system loss factor.

In the real environment the distribution of radio signal strength used for positioning or localization, depends on the environment and presence of objects that very often disturbs line of sight propagation (walls, furniture, people).

In the literature two main approaches to RSSI positioning are distinguished. First one is typical for small undisturbed areas and is based on the direct utilisation of path loss model. The second approach is based on preliminary empirical determination of radio signal strength map, to which coordinates are associated. In this method the entire positioning process is divided in two phases: training phase and tracking phase [2]. In the first stage a map of radio signal strength is prepared using a fingerprint and interpolation technique (for example k-nearest neighbours) [27].

Despite many advantages of modern navigation systems, there are applications where navigation systems have serious outages. Some systems operates properly only outdoors, accuracy some degrade with time, some have too small coverage. There is a lot of research on how to fulfil these outages. Two main directions of these research are sensor fusion (integrated navigation) and cooperative/collaborative navigation. First one focuses on the use of multiple sensors embedded in one platform using various algorithms (Kalman 
filtering [10], Bayesian integration [1]). Second one uses multiple moving objects and measured distances between these objects to provide relative position [9, 16]. This is used for example in swarm of robots navigation [7].

The accuracy and efficiency of various position or localization systems can be improved using sensor fusion. This concept is based on the connection of various positioning and communication systems for example ultrasound system with laser and Wi-Fi positioning.

Another approach to sensor fusion is to combine various network technologies such as Bluetooth, Wi-Fi and ZigBee [27].

\section{ZIGBEE PHASE-SHIFT MEASUREMENTS}

In [8] a review of parameters important for RF positioning networks is presented. Following parameters are described: coverage, positioning model, type, topology, performance, sensor fusion, positioning phases and application.

AT86RF233 is a $2.4 \mathrm{GHz}$ transceiver (from ATMEL) based on ZigBee protocol. In this device, next to TOF module, a phase measurement unit (PMU) is introduced. PMU and TOF modules can be used for a geometry-based positioning or proximity detection. Additionaly RSSI can be used for geometry - free positioning.

Unlike the TOF, where distance is calculated on the basis of the round trip time, in the phase shift method the carrier wave is modulated sinusoidally, and round-trip time is turned into phase shift [21]:

$$
\Delta \Phi=2 \pi f \frac{2 d}{c}
$$

Where $f$ is a frequency hub, $c$ is the speed of electromagnetic wave propagation, $d$ is a distance and $\Delta \Phi$ is a phase shift. When measured distance is greater than one cycle phase ambiguities must be taken into account. It can be resolved using TOF ranging or some search method [14].

For the purpose of this experiment, to measure the distances, wireless nodes based on the REB233CBB hardware platform with dedicated software (RTB Evaluation Application) were used
[25]. Each node consists of REB233SMAD radio extender with AT86RF233 radio transceiver and a PCB with AtxMega256A3 micro-controller. A PC computer is used as main user interface. The communication between PC and REB233CBB is performed using USB. Scheme of this device is depicted in Fig. 3.

In every single distance measurement two nodes, namely initiator and reflector, are involved. Single ranging is carried out according to the flowchart presented in Fig. 4.

In "ranging initiation phase", which starts with sending a request from initiator, the ranging capabilities are negotiated between initiator and reflector. The request for antenna diversity is included in this stage. After performing subsequent phases, namely "timing synchronization" and "ranging start phase" the proper ranging procedure is carried out. This procedure is based on the measurement of phase shift corresponding to measured distance between nodes. It is repeated for a set of frequencies defined during the initiation phase.

In the "data transfer" and "distance calculation" phases, obtained measurement results are processed according to equation 4 and distances along with corresponding DQF values are returned.

$$
D=\frac{c}{4 \pi} \frac{-1 \sum_{N-1} \Delta \phi_{n}}{(N-1) \Delta f}
$$

Where $D$ is a measured distance, $c$ is speed of light, $\Delta f$ is a frequency increment and $\Delta \varphi$ is a phase shift.

Each node is equipped with two antennas placed $12.5 \mathrm{~cm}$ from each other. These antennas can be switched by AT86RF233 in order to reduce the multipath or fading effect (so called "antenna diversity"). Hence, for each anchor-rover distance measurement a set of four distance - DQF pairs is returned by the evaluation application (Fig. 5). The signal used for distance measurement is strongly affected by a multipath effect, especially in the indoor environment. The idea of "antenna diversity" is to analyse these four pairs of data in order to select the one reflecting line-of-sight propagation.

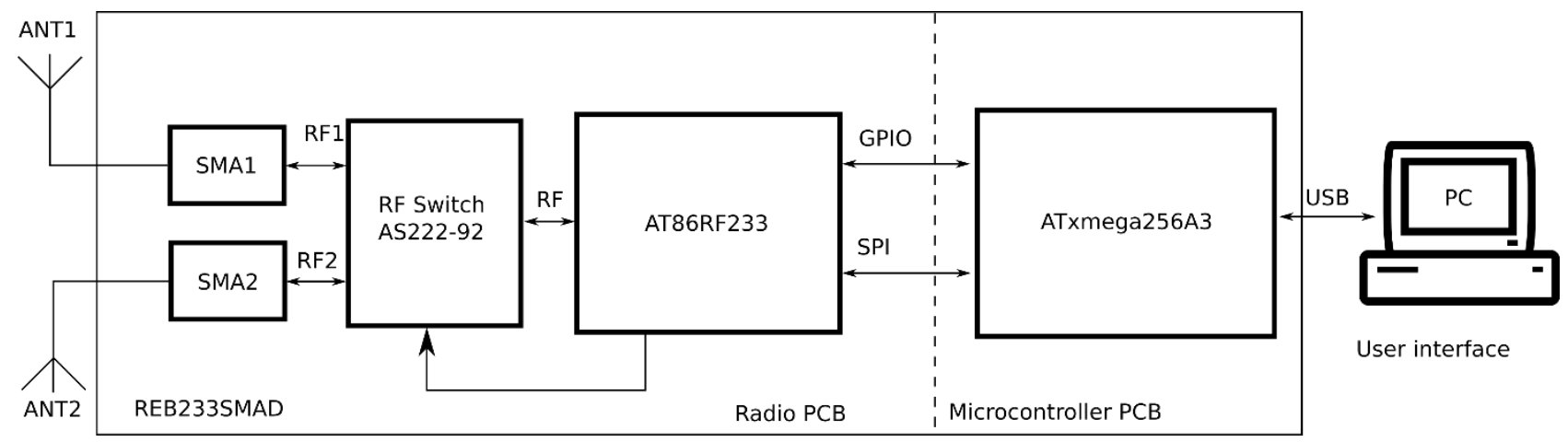

Fig. 2. Scheme of the equipment use in the experiment 


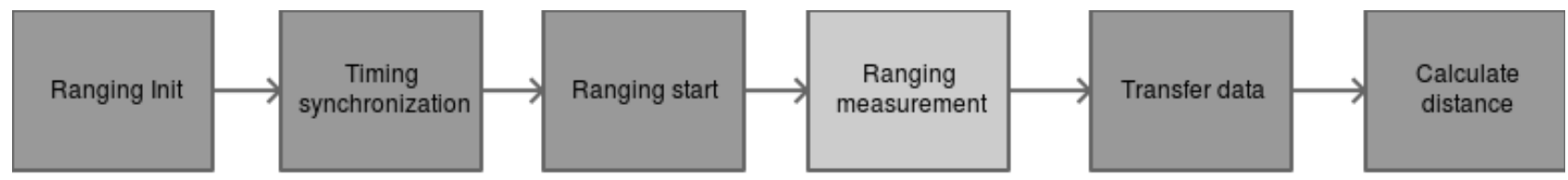

Fig. 3. Ranging procedure

In order to perform and validate some measurements a test site was established. It consists of four fixed points used to place anchors and a reference point used to place rover (Fig. 6). The coordinates of these points were obtained using geodetic surveying techniques. The mean errors of established point location were smaller than $1 \mathrm{~cm}$. The rover played the initiator role and each anchor was a reflector.

\section{PRELIMINARY RANGING AND POSITIONING RESULTS}

The preliminary results were calculated using a sample of 300 observations to four anchors. Various approaches to calculate position using trilateration exists in the literature [26]. In this paper to calculate the results a Kalman filter was used [3]. For positioning the pair of antennas with best DQF value was selected in each epoch. The selected distance measurements used in this example are depicted in Figure 6. The left side of this figure depicts distances measured to four anchors. The right side presents corresponding $\mathrm{DQF}$ values. It can be observed, that there is a lot of outliers in distances, which degrades the performance of positioning. In position calculation DQF values were used as weights.

The positioning results are depicted in Fig. 7. Circles represents results from each consecutive epoch. Single epoch position is contaminated with a lot of noise, but mean position after 300 epochs is very close to the reference position of the rover.

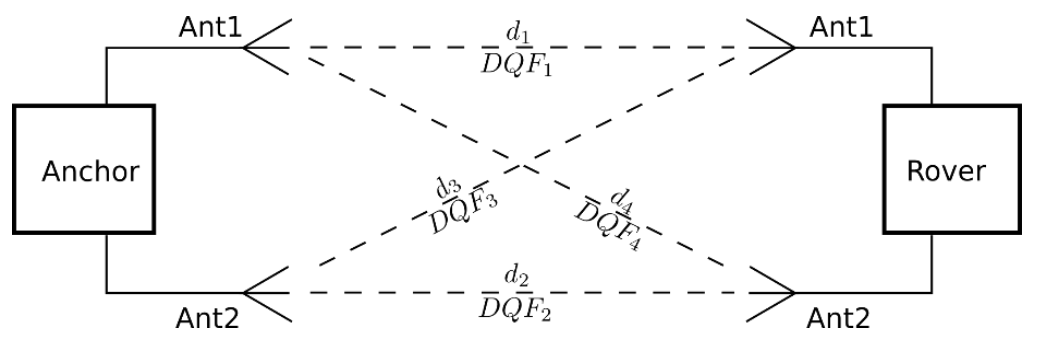

Fig. 4. The scheme of antenna diversity
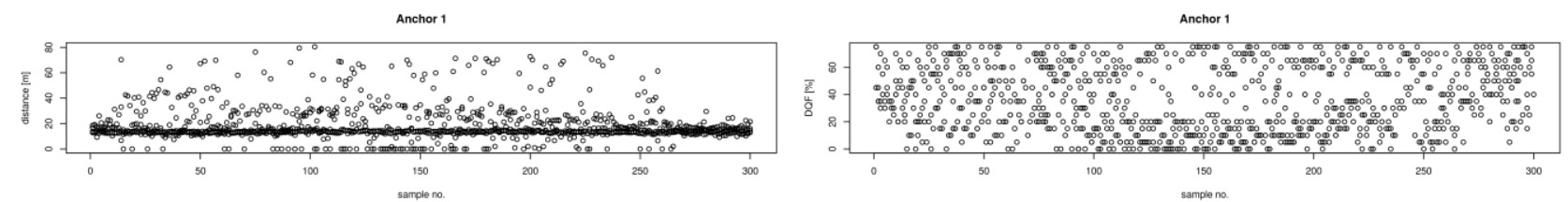

Anchor 2
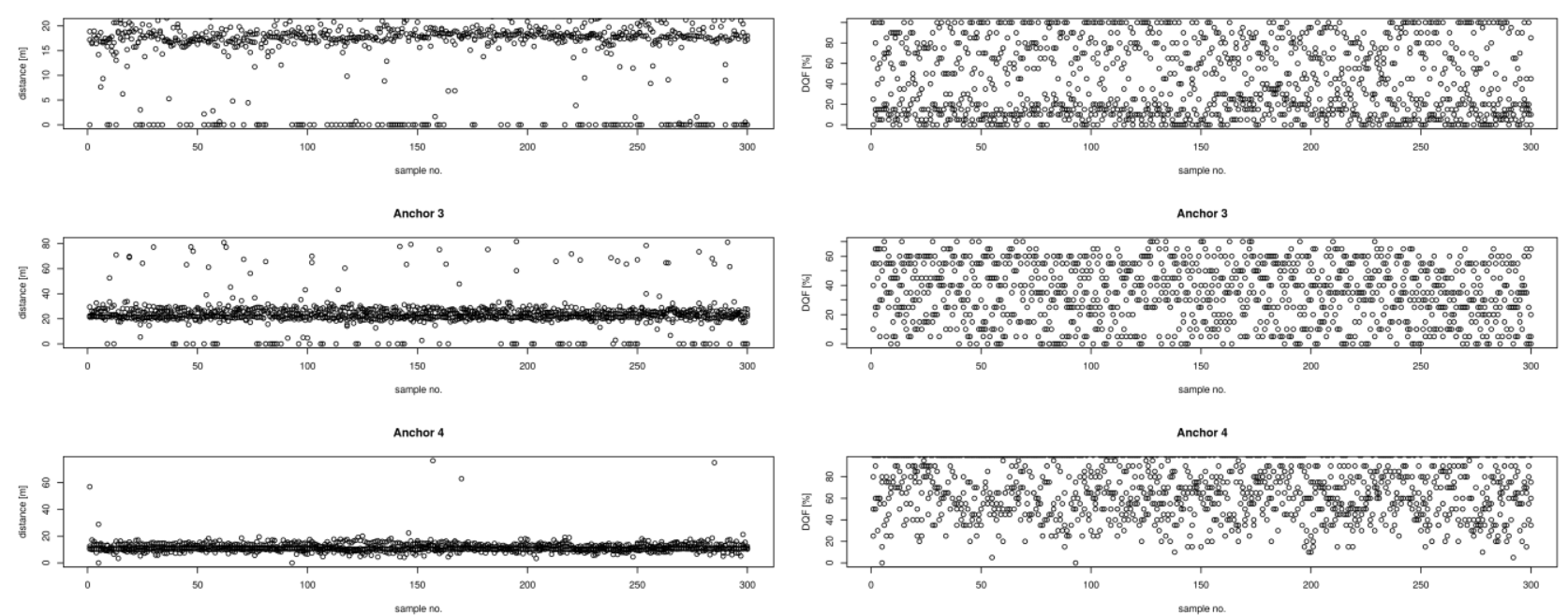

Fig. 5. Ranging results 


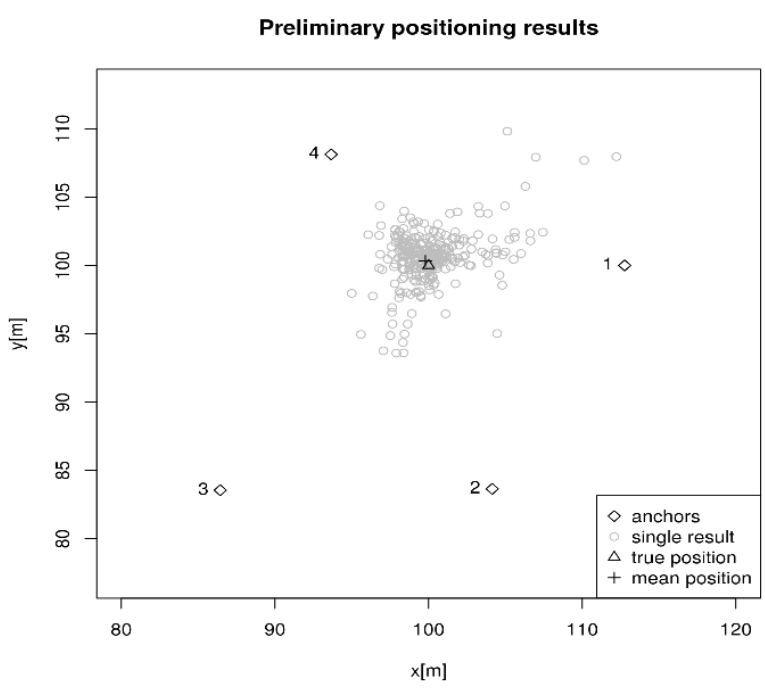

Fig. 6. Positioning results

Nevertheless, in this example, resulting mean residual of position is $21 \mathrm{~cm}$ in $\mathrm{x}$ direction and 30 $\mathrm{cm}$ in $\mathrm{y}$ direction. This shows that some pre processing of measurements is required to obtain more accurate results. Figure 8 depicts the distribution of the positioning results in $\mathrm{x}$ and $\mathrm{y}$ plane.

One of the important issues in indoor navigation and positioning is location of anchors during the infrastructure design stage. This issue is described in $[12,13]$.

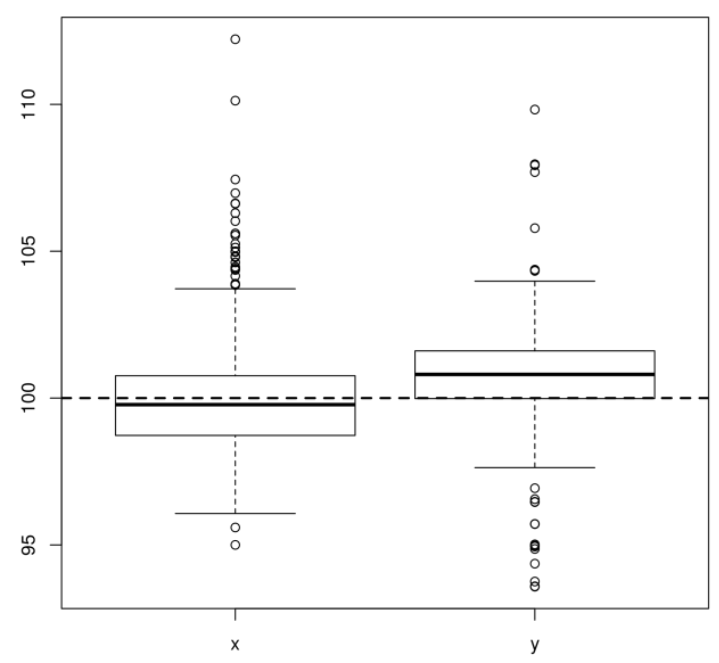

Fig. 7. Boxplot of the positioning results in $\mathrm{X}$ and $\mathrm{Y}$ direction $[\mathrm{m}]$

\section{CONCLUSION}

In this paper a phase measurement unit embedded into ZigBee device is presented against a background of existing indoor positioning techniques. Basics of operation principles of most common RF indoor positioning techniques are presented. The preliminary distance measurements were performed and position was calculated.
Preliminary tests shows that ZigBee PMU enabled device gives the opportunity to perform ranging in a mesh ZigBee networks. Initial accuracy estimation based on the preliminary positioning results is in the range of tens of centimetres. The results encourages for further research on the performance, algorithms, multipath rejection or antenna diversity.

\section{REFERENCES}

1. Abidi M, Gonzales R. Data fusion in robotics \& machine intelligence. Academic Press. 1992.

2. Adalja DM. A comparative analysis on indoor positioning Techniques and Systems. Int. J. Eng. Res. 2013;3: 1790-1796.

3. Anderson BDO, Moore JB. Optimal Filtering. Dover Publications, Mineola. NY. 2005.

4. Chen Q, Liu H, Yu M, Guo H. RSSI ranging model and 3D indoor positioning with ZigBee network. in: Position Location and Navigation Symposium (PLANS), 2012.

https://doi.org/10.1109/PLANS.2012.6236979

5. Cobb HS. GPS pseudolites: Theory, design, and applications. Stanford University. 1997.

6. Cobb HS, Cohen CE, Parkinson BW. Theory and design of pseudolites, in: Proceedings of the 1994 National Technical Meeting of The Institute of Navigation. 1994: 69-75.

7. Ducatelle F, Caro GAD, Gambardella LM. Robot navigation in a networked swarm. in: Xiong C, Huang Y, Xiong Y, Liu H. (Eds.), Intelligent Robotics and Applications, Lecture Notes in Computer Science. Springer Berlin Heidelberg. 2008: 275-285.

8. Farid Z, Nordin R, Ismail M. Recent Advances in Wireless Indoor Localization Techniques and System. J. Comput. Netw. Commun. 2013. https://doi.org/10.1155/2013/185138

9. Grejne-Brzezinska D, Toth CK. GNSS-challenged environments: can collaborative navigation help? Journal of Aeronautics, Astronautics and Aviation. Series A. 2013; 12(01):24-248. https://doi.org/10.6125/13-0902-766

10. Hao Y, Guo Z, Sun F, Gao W. Adaptive Extended Kalman Filtering for SINS/GPS Integrated Navigation Systems. IEEE, 2009: 192-194. https://doi.org/10.1109/CSO.2009.429

11. Indelman V, Gurfil $\mathrm{P}$, Rivlin $\mathrm{E}$, Rotstein $\mathrm{H}$. Distributed vision-aided cooperative localization and navigation based on three-view geometry, in: 2011 IEEE Aerospace Conference. https://doi.org/10.1109/AERO.2011.5747546

12. Janicka J, Rapinski J. An example and analysis for ambiguity resolution in the indoor ZigBee positioning system. Reports on Geodesy and Geoinformatics. 2017; 103:1-9, https://doi.org/10.1515/rgg-2017-0001

13. Janowski A, Rapinski J. Augmentation of GNSS autonomous positioning using a ground based ZigBee phase shift distance measurement. "Environmental Engineering" 10th International Conference Vilnius Gediminas Technical University Lithuania. 2017.

14. Janowski A, Rapinski J. The analyzes of PDOP factors for a ZigBee ground-based. Polish Maritime Research. 2017. 24(s1): 108-114. https://doi.org/10.1515/pomr-2017-0028 
15. Joana Halder S, Kim W. A fusion approach of RSSI and LQI for indoor localization system using adaptive smoothers. J. Comput. Netw. Commun. 2012,.https://doi.org/10.1155/2012/790374

16. Lee JK, Grejner-Brzezinska. DA, Toth C. Networkbased Collaborative Navigation in GPS-Denied Environment. J. Navig. 2012; 65. https://doi.org/10.1017/S0373463312000069

17. Kee C, Jun H, Yun D, Kim B, Kim Y, Parkinson BW, Langenstein T, Pullen S. Lee J. Development of indoor navigation system using asynchronous pseudolites. Proceedings of the 13th International Technical Meeting of the Satellite Division of The Institute of Navigation. 2012: 1038-1045.

18. Lourenco P, Batista P, Oliveira P, Silvestre C, Chen P. A received signal strength indication-based localization system, 21st Mediterranean Conference on Control Automation (MED). 2013: 1242-1247. https://doi.org/10.1109/MED.2013.6608878

19. Maisano DA, Jamshidi J, Franceschini F, Maropoulos PG, Mastrogiacomo L, Mileham A, Owen G. Indoor GPS: system functionality and initial performance evaluation. Int. J. Manuf. Res. 2008;3:335-349.

20. Narmada A, Sudhakara R. Performance comparison of routing protocols for ZigBee WPAN. IJCSI International Journal of Computer Science. 2011; 6(2):394-402.

21. Nejad S, Olyaee S. Comparison of TOF, FMCW and Phase-Shift Laser Range-Finding Methods by Simulation and Measurement. Quartarly J. Technol. Educ. 2006; 1: 11-18.

22. Peng R, Sichitiu ML. Angle of arrival localization for wireless sensor networks. 3rd Annual IEEE Communications Society on Sensor and Ad Hoc Communications and Networks, 2006: 374-382. https://doi.org/10.1109/SAHCN.2006.288442

23. Rapinski J, Cellmer S, Rzepecka Z. Modified GPS/Pseudolite Navigation Message. J. Navig. 2012; 65: 711-716. https://doi.org/10.1017/S0373463312000124

24. Rapinski J, Koziar M, Rzepecka Z, Cellmer S, Chrzanowski A. Some considerations in designing a GPS pseudolite. Artif. Satell. 2012; 47: 1-11. https://doi.org/10.2478/v10018-012-0009-7

25. Rapinski J, Smieja M. ZigBee ranging using phase shift measurements. The Journal of Navigation. 2015; 68(4): 665-677, https://doi.org/10.1017/S0373463315000028

26. Rapinski J, Cellmer S. Analysis of range based indoor positioning techniques for personal communication networks. Mobile Networks and Apllications. 2015, https://doi.org/10.1007/s11036-015-0646-8

27. Rodrigues ML, Vieira LFM, Campos MFM. Fingerprinting-based radio localization in indoor environments using multiple wireless technologies. IEEE 22nd International Symposium on Personal Indoor and Mobile Radio Communications (PIMRC). 2011 1203-1207. https://doi.org/10.1109/PIMRC.2011.6139691

28. Shen X, Wang Z, Jiang P, Lin R, Sun Y. Connectivity and RSSI based localization scheme for wireless sensor networks. in: Huang, DS, Zhang XP, Huang GB. (Eds.), Advances in Intelligent Computing, Lecture Notes in Computer Science. Springer Berlin Heidelberg. 2005: 578-587.

29. Turk MA, Morgenthaler DG, Gremban KD, Marra M. VITS-a vision system for autonomous land vehicle navigation. IEEE Trans. Pattern Anal. Mach. Intell. 1988:10, 342-361. https://doi.org/10.1109/34.3899

30. Van Diggelen F, Abraham C. Indoor GPS technology. CTIA Wirel. Agenda Dallas, 2001.

31. Friis HT. A Note on a Simple Transmission Formula. Proceedings of the IRE. 1946;34(5): 254-256. https://doi.org/10.1109/JRPROC.1946.234568.

\section{Received 2018-06-18}

Accepted 2018-08-31

Available online 2018-09-03

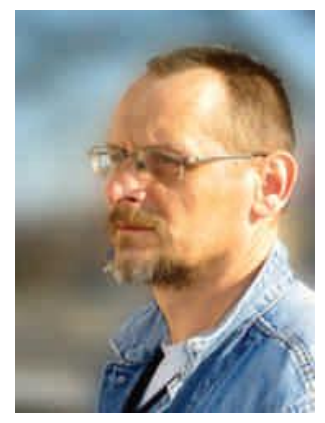

Michal ŚMIEJA DEng. -
doctor in the Faculty of
Technical Sciences at
University of Warmia and
Mazury in Olsztyn He is
member of the Polish Society
of Technical Diagnostics since
2016. His main interest focus
on the use of the
communication end embedded
solutions in control and
diagnostic mechatronic
systems.

